\title{
Orofacial findings in chronic granulomatous disease: report of twelve patients and review of the literature
}

\author{
Najla S Dar-Odeh 1*, Wail A Hayajneh², Osama A Abu-Hammad', Huda M Hammad³, Adel M Al-Wahadneh4, \\ Najwa K Bulos ${ }^{5}$, Azmi M Mahafzah ${ }^{6}$, Maha S Shomaf ${ }^{6}$, Mohammed A El-Maaytah7, Faris G Bakri ${ }^{8}$
}

\begin{abstract}
Background: Chronic granulomatous disease is an extremely rare primary immunodeficiency syndrome that can be associated with various oral complications. This can affect high number of patients. However, data on oral complications is sparse. Here we will review the literature and describe the orofacial findings in 12 patients.

Findings: The age range was 5-31 years. Oral findings were variable, and reflected a low level of oral hygiene. They included periodontitis, rampant caries, gingivitis, aphthous-like ulcers, and geographic tongue. One patient had white patches on the buccal mucosa similar to lichen planus. Another patient had a nodular dorsum of the tongue associated with fissured and geographic tongue. Biopsies from the latter two lesions revealed chronic nonspecific mucositis. Panoramic radiographs showed extensive periodontitis in one patient and periapical lesions in another patient.

Conclusion: Patients with chronic granulomatous disease may develop oral lesions reflecting susceptibility to infections and inflammation. It is also possible that social and genetic factors may influence the development of this complication. Therefore, oral hygiene must be kept at an optimum level to prevent infections that can be difficult to manage.
\end{abstract}

\section{Background}

Chronic granulomatous disease (CGD) is an extremely rare congenital immune deficiency syndrome with an incidence of 1:250,000 individuals. It is characterized by recurrent severe infections due to the inability of neutrophils and macrophages to mount a respiratory burst and kill invading bacteria and fungi. The disease is caused by nicotinamide adenine dinucleotide phosphate (NADPH) oxidase deficiency which results from mutation in one of the four components of the NADPH oxidase complex. The most frequent form is the $\mathrm{X}$ linked (XCGD), with mutations in $C Y B B$ gene encoding gp91phox subunit. Rare subgroups are caused by mutations in CYBA, NCF1 or NCF2 genes encoding p22phox, p47phox or p67phox subunits respectively $[1,2]$

CGD patients usually present in the first few years of life with cervical or inguinal lymphadenitis, liver

\footnotetext{
* Correspondence: najla_dar_odeh@yahoo.com

${ }^{1}$ Faculty of Dentistry, University of Jordan, Amman, Jordan
}

abscesses, osteomyelitis, pneumonia, or skin infections $[1,2]$. In addition, CGD patients also suffer from infections and sterile hyperinflammation in the oral cavity [3]

In CGD, oral complications are generally considered to be minor infections as they are not life-threatening. Several reports describe oral ulcers [4-9], including one case with multiple buccal mucosal ulcers in direct contact with dental plaque [4]. Other findings include periodontal involvement such as severe gingivitis [4-6], periodontitis $[4,6]$, generalized pre-pubertal periodontitis [10], granulomatous mucositis in the upper lip [11] and the soft palate [12], geographic tongue [9], oral candidiasis [13], and enamel hypoplasia [9]. However, it is not clear to what extent these complications can be attributed specifically to CGD since many of them are also common in the general population [3].

Histological findings of oral lesions have generally shown inflammation; Wysocki and Brooke [14] described an ulcerative lesion showing inflammatory cell infiltrate consisting of plasma cells, histiocytes, and 
occasional eosinophils. This is in addition to small granulomas characterized by mononuclear histiocytes and occasional multinucleated giant cells. One of the granulomas exhibited a central focus of necrosis containing moderate numbers of neutrophils and eosinophils. Another report by Dusi et al [11] described chronic inflammation and non-caseating granuloma composed of many epithelioid cells, a few giant cells, edema, and dilated lymphatic vessels in the superficial dermis in the biopsy of an upper lip granulomatous cheilitis. Furthermore, Cohen et al [6] also showed acute and non-specific inflammation from oral ulcers biopsies.

The frequency of oral complications in CGD is variable and can range from few cases in some large series $[1,15,16]$, to as high as $35 \%$ in other studies [17]. Therefore, these complications could be a major cause of morbidity in patients with CGD. However, despite this occasional high frequency and potential morbidity, these complications have rarely been investigated [3].

Factors that predispose to CGD related oral complications include neutrophil dysfunction [18,19]; malnutrition due to gastrointestinal complications such as gastric outlet obstruction, colitis-enteritis, and diarrhoea $[20,21]$. Also included are autoimmune mechanisms [22]; and possibly immunosuppressive therapy, particularly steroids, which may be given to patients with granulomatous lung or inflammatory bowel disease [23]. Other factors for periodontal diseases that may occur in CGD patients, but are not specific to CGD, include smoking, poor oral hygiene, and emotional stress [23].

Here, we describe the oral findings in 12 CGD patients including the histological findings of oral lesions in two of them.

\section{Findings}

Twelve CGD patients, from eight families, were referred from 3 major hospitals in Jordan. Patients A3, A4, D4, E8, and E10 suffered from a mutation in NCF1; $\mathrm{C} 1$ and F5 from a mutation in NCF2; J2 and J3 from a mutation in $C Y B A$; $\mathrm{B} 1$ and $\mathrm{B} 2$ from an autosomal recessive type with unidentified mutation. Patient K1 was the only patient with the $\mathrm{X}$ linked form, he suffered from a rare $\mathrm{X} 91^{+}$type. All patients were taking prophylactic itraconazole and trimethoprim-sulfamethoxazole, but on an intermittent basis. The full clinical and molecular characteristics of these patients were previously published [24]. Dental and medical histories, including drug intake, history of oral hygiene, and clinical oral examination were performed and documented for all patients. Panoramic radiographs, to detect any bony or dental pathology, were performed for all patients except patient B2 as she was uncooperative. Gingivitis index was measured and oral mucous membranes were examined for any abnormalities particularly ulcers. Specific oral lesions were seen in two patients, and these were subsequently biopsied.

\section{Orofacial findings}

A3: Thirty-one year old man with grade 3 gingivitis, multiple carious teeth, badly distracted teeth, and submental salivary gland enlargement. Panoramic radiograph showed extensive periodontitis of the remaining roots apices.

A4: Twenty-six year old man with grade 3 gingivitis, rampant caries, 4 missing teeth, periodontitis, geographic and fissured tongue, macroglossia, and smoker's melanosis (Figure 1). Multiple periapical lesions were observed in his panoramic radiograph related to badly decayed lower molar teeth (Figure 2), which were later extracted. A nodular lesion in the center of the anterior two thirds of the dorsum of the tongue was biopsied (figures 3 and 4).

B1: Thirteen year old boy with 3 carious deciduous teeth.

B2: Six year old girl, and sister of B1, with grade 1 gingivitis and rampant caries. She also had extrinsic staining on her teeth due to chronic intake of sugarcontaining iron supplements.

C1: Fifteen year old boy with a coated tongue, aphthous-like ulcers and traumatic lip lacerations.

D4: Thirteen year old boy with grade 1 gingivitis and carious lower first molars.

E8: Fifteen year old boy with grade 1 gingivitis, fissured tongue. He also had characteristic white patches mimicking reticular lichen planus located on the buccal mucosa anteriorly and bilaterally, and on the junction between hard and soft palate (figure 5).

E10: Eleven year old boy, and brother of E8 with grade 1 gingivitis and 8 carious deciduous teeth.

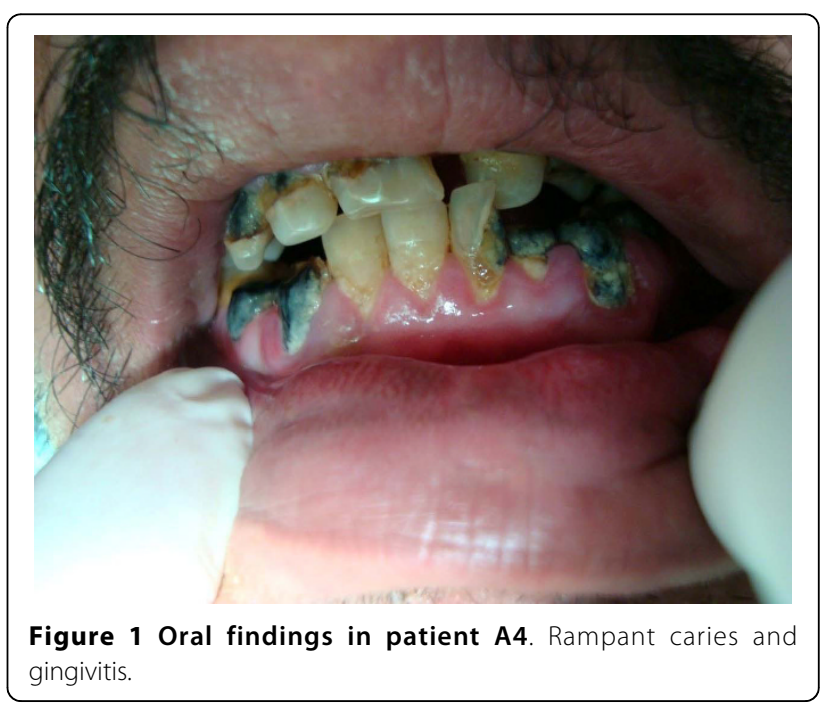




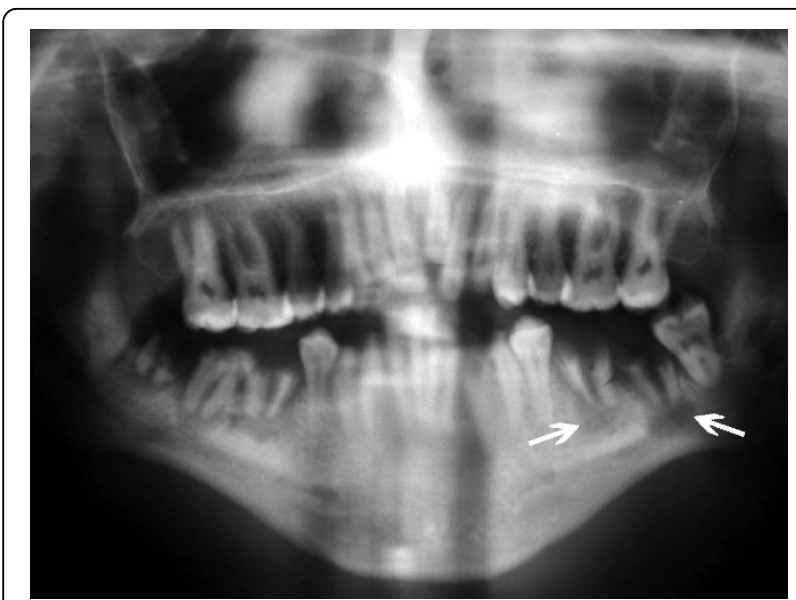

Figure 2 Oral findings in patient A4. A panoramic radiograph showing multiple periapical lesions related to lower molars (arrows).

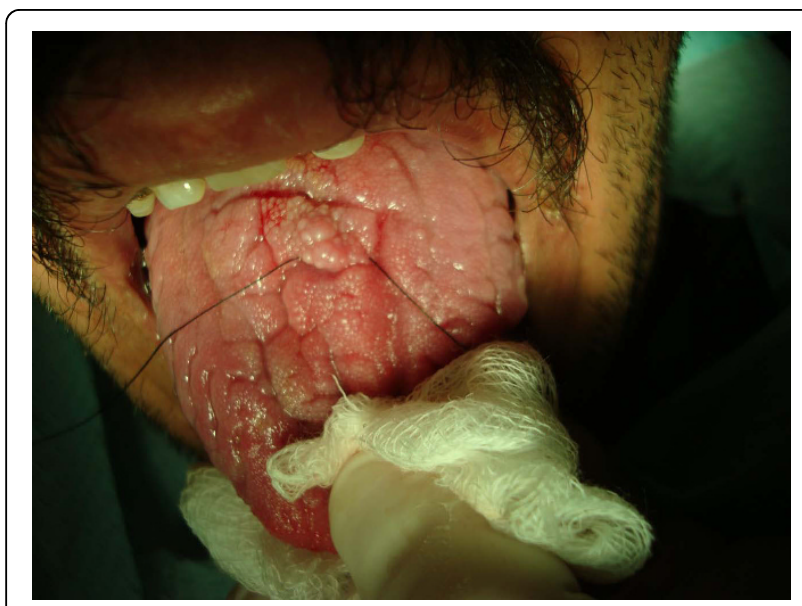

Figure $\mathbf{3}$ Oral findings in patient $\mathbf{A} \mathbf{4}$. Geographic tongue and the site of nodular lesion biopsy.

F5: Seven year old girl with grade 1 gingivitis related to lower incisors.

J2: Seven year old girl with grade 3 gingivitis, rampant caries affecting 8 teeth and a geographic tongue. Five of her molars were in the form of remaining roots.

J3: Five year old girl, and sister of J2 with grade 3 gingivitis, 9 carious teeth and a geographic tongue. She had an abscess related to lower right molars with right submandibular lymphadenopathy.

K1: Fourteen year old boy with grade 3 gingivitis, facial scarring, and a facial wart.

\section{Histological findings}

A4: An incisional biopsy of the nodular lesion on the center of anterior two thirds of the tongue showed hyperkeratosis, acanthosis, and mild diffuse chronic non-specific mucositis (Figure 4).

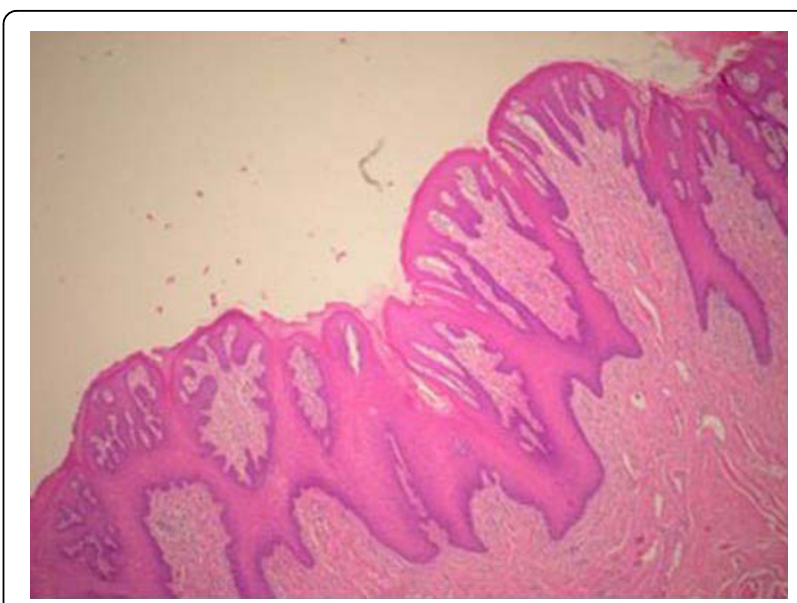

Figure 4 Oral findings in patient A4. Hyperkeratosis, acanthosis, and diffuse chronic nonspecific mucositis ( $H \& E, \times 40)$.

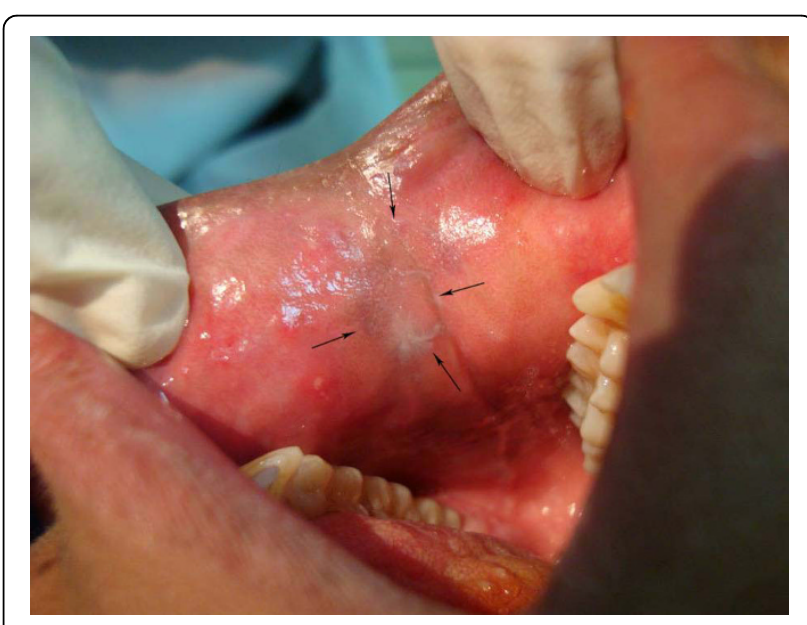

Figure 5 Oral findings in patient E8 showing white lesions (arrows) in the form of thin striations affecting the buccal mucosa.

E8: The incisional biopsy taken from the white lesion in the right buccal mucosa showed mild hyperparakeratosis of surface epithelium, moderate fibrosis of the lamina propria with diffuse chronic non-specific mucositis, and mild chronic sialadenitis with occasional focal lymphocytic aggregates.

\section{Radiological findings}

Panoramic radiographs did not show any specific lesions except in patient A3 and A4; A3 had extensive periodontitis of the remaining roots apices. A4 had multiple periapical lesions mainly due to neglect of oral hygiene with subsequent caries and pulpal involvement (Figure 2).

\section{Discussion}

Patients in this study had variable oral manifestations. The severity of gingivitis and carious lesions was also 
variable. Unfortunately poor oral hygiene was observed in all patients in various degrees resulting in plaqueinduced gingivitis and rampant caries (Figure 1). Six (50\%) patients (A3, A4, B2, J2, J3, and E10) had rampant caries and multiple carious teeth. Periodontitis was observed in A3 and A4. Aphthous-like ulcers were observed in C1. Overall there were 7 (58\%) patients suffering from significant oral complications. This is among the highest reported frequency [17]. However, accurate comparison to other reports is not possible due to: lack of detailed description of oral lesions in other reports, the small size of this series, and abundance of recessive type of CGD contrary to most reports where XCGD is the most common type. We also could not establish a relation between the severity of oral disease and CGD genotypes.

The oral health of the patients was neglected. The low level of oral hygiene and the inadequate use of a tooth brush may be attributed to the poor awareness of both the patients and their families to the importance of oral hygiene practices. Another cause seems to be the focus of parents on the general poor health of their children rather than on their oral hygiene.

Geographic tongue was observed in 3 (27\%) patients (A4, J2, and J3), two of them who were sisters. However, although this association has been reported previously [9], it is unclear of it sigificance as this was a small sample, and the prevalence of geographic tongue in Jordan is approximately $7 \%$ [25].

In CGD, inflammation at multiple sites may lead to formation of exuberant tissue granulomas which can obstruct the larynx, oesophagus, or other regions of the gastrointestinal tract [26]. Biopsies of oral mucosa in our patients did not show granulomas. Rather, they showed non-specific mucositis with occasional lymphocytic aggregates. This is not surprising since CGD may present in a wide range of tissue specimens, most often demonstrating features of active chronic inflammation with or without granuloma formation [27].

The rate and severity of oral disease varies across different studies; one study [17] found rates of $35 \%$ while several other large studies $[1,15,16,26,28,29]$ found low rates ranging from 0 to $26 \%$. In our series we found a high rate of oral disease. This could be a specific finding in autosomal recessive types, or it could be due to factors other than CGD. These factors include neglect in oral hygiene, which was observed in all our patients. It is known that the most common factor for periodontal disease is the periodontal biofilm which forms on the teeth in the absence of effective oral hygiene [30]. Another factor is the possible genetic susceptibility related to the Jordanian study population as the prevalence of periodontitis varies between different races [31]. This is because genetic factors may play a role in periodontitis, the phenotype of which is determined by both the genetic makeup and the environmental influences on the patient [32]. Subsequently, our findings may not necessarily apply to CGD patients from other ethnicities and regions. Moreover, the abundance of autosomal recessive types of CGD here suggests the presence of co-segregated genes for periodontitis; similar to the previously described co-segregation of a neutrophil abnormality trait with localized aggressive periodontitis $[33,34]$. Furthermore, periodontitis has been reported with several rare genetic syndromes such as leukocyte adhesion deficiency, Ehler - Danlos syndrome type 8, and Lowe syndrome indicating the variety of genes that can predispose to periodontal disease [35].

Thirty years ago Wysocki and Brooke [14] noted that the oral manifestation of CGD was briefly alluded to, and variously described as, "ulcerative stomatits", "compatible with aphthous stomatitis", and "stomatitis". Today, this observation is still valid as most studies in CGD still refer to the oral complications with the same non specific terminology such as "gingivostomatitis" [17], "ulcerative stomatits", "gingivitis", and "periodentitis" $[1,28,36]$ making it difficult both to make accurate comparisons between studies, and to describe the spectrum of the oral lesions. We therefore suggest that more specific terms be used instead to describe the oral manifestations in CGD.

\section{Conclusion}

This study shows that CGD patients may have a high frequency and variable presentations of oral complications. Other social and genetic factors may influence the development of such complications. On a histological level, they may develop nonspecific chronic mucositis characterized by lymphocytic aggregation. The oral cavity can be a potential source of infection, especially if oral hygiene is neglected. Specialized dental care and regular dental attendance are crucial in the management of these patients.

\section{Acknowledgements}

This work was supported by a grant from the University of Jordan, Amman, Jordan.

The authors wish to thank Mrs. Marie El-Maaytah for proof editing the manuscript.

\section{Author details}

${ }^{1}$ Faculty of Dentistry, University of Jordan, Amman, Jordan. ${ }^{2}$ Department of Pediatrics, Jordan University of Science and Technology, Irbid, Jordan.

${ }^{3}$ Department of Oral Medicine and Surgery, Jordan University of Science and Technology, Irbid, Jordan. ${ }^{4}$ Department of Pediatrics, King Hussein Medical Centre, Amman, Jordan. ${ }^{5}$ Department of Pediatrics, Jordan University Hospital, Amman, Jordan. ${ }^{6}$ Department of Pathology and Microbiology, Jordan University Hospital. Amman, Jordan. ${ }^{7}$ Division of Oral \& Maxillofacial Medical, Surgical \& Diagnostic Services, UCL Eastman Dental Institute, London, UK. ${ }^{8}$ Department of Internal Medicine, Jordan University Hospital, Amman, Jordan. 


\section{Authors' contributions}

$\mathrm{ND}$, designed the study, examined the patients, analyzed the data, and wrote the paper. OA, co-designed the study, participated in examining the patients, and in writing the paper. $\mathrm{HMH}$, examined the patients. WAH, included the patients, and participated in writing the paper. NKB and AMA, included the patients in the study. MSS, performed the pathological reading on the biopsies. AM and MAE helped to draft the manuscript. FGB, conceived the study, supervised inclusion of patients, participated in both the study design, and the manuscript drafting. All authors read and approved the final manuscript.

\section{Competing interests}

The authors declare that they have no competing interests.

Received: 16 September 2009

Accepted: 17 February 2010 Published: 17 February 2010

\section{References}

1. Winkelstein JA, Marino MC, Johnston RB Jr, Boyle J, Curnutte J, Gallin Jl, Malech HL, Holland SM, Ochs H, Quie P, Buckley RH, Foster CB, Chanock SJ, Dickler $\mathrm{H}$ : Chronic granulomatous disease. Report on a national registry of 368 patients. Medicine (Baltimore) 2000, 79:155-169.

2. Stasia MJ, Li XJ: Genetics and immunopathology of chronic granulomatous disease. Semin Immunopathol 2008, 30:209-235.

3. Giannopoulou C, Krause KH, Muller F: The NADPH oxidase NOX2 plays a role in periodontal pathologies. Semin Immunopathol 2008, 30:273-278.

4. Wolf JE, Ebel LK: Chronic granulomatous disease: report of case and review of the literature. J Am Dent Assoc 1978, 96:292-295.

5. Charon JA, Mergenhagen SE, Gallin Jl: Gingivitis and oral ulceration in patients with neutrophil dysfunction. J Oral Pathol 1985, 14:150-155.

6. Cohen MS, Leong PA, Simpson DM: Phagocytic cells in periodontal defense. Periodontal status of patients with chronic granulomatous disease of childhood. J Periodontol 1985, 56:611-617.

7. Landing BH, Shirkey HS: A syndrome of recurrent infection and infiltration of viscera by pigmented lipid histiocytes. Pediatrics 1957 , 20:431-438.

8. De Ravin SS, Naumann N, Cowen EW, Friend J, Hilligoss D, Marquesen M, Balow JE, Barron KS, Turner ML, Gallin JI, Malech HL: Chronic granulomatous disease as a risk factor for autoimmune disease. J Allergy Clin Immunol 2008, 122:1097-1103.

9. Scully C: Orofacial manifestations of chronic granulomatous disease of childhood. Oral Surg Oral Med Oral Pathol 1981, 51:148-151.

10. Buduneli N, Baylas H, Aksu G, Kutukculer N: Prepubertal periodontitis associated with chronic granulomatous disease. I Clin Periodontol 2001, 28:589-593.

11. Dusi S, Poli G, Berton G, Catalano P, Fornasa CV, Peserico A: Chronic granulomatous disease in an adult female with granulomatous cheilitis. Evidence for an X-linked pattern of inheritance with extreme Iyonization. Acta Haematol 1990, 84:49-56.

12. Miller $\mathrm{R}$, Myer $\mathrm{CM}$, Gray $\mathrm{S}$ : Otolaryngologic manifestations of chronic granulomatous disease. Am J Otolaryngol 1988, 9:79-82.

13. Movahedi M, Aghamohammadi A, Rezaei N, Farhoudi A, Pourpak Z, Moin M, Gharagozlou M, Mansouri D, Arshi S, Atarod L, Mirsaeid Ghazi B, Shahnavaz N, Babaei Jandaghi A, Abolmaali K, Mahmoudi M, Bazargan N, Ahmadi Afshar A, Nabavi M: Gastrointestinal manifestations of patients with chronic granulomatous disease. Iran J Allergy Asthma Immunol 2004, 3:83-87.

14. Wysocki GP, Brooke Rl: Oral manifestations of chronic granulomatous disease. Oral Surg Oral Med Oral Pathol 1978, 46:815-819.

15. Hasui M: Chronic granulomatous disease in Japan: incidence and natural history. The Study Group of Phagocyte Disorders of Japan. Pediatr Int 1999, 41:589-593.

16. Ahlin A, De Boer M, Roos D, Leusen J, Smith Cl, Sundin U, Rabbani H, Palmblad J, Elinder G: Prevalence, genetics and clinical presentation of chronic granulomatous disease in Sweden. Acta Paediatr 1995, 84:1386-1394

17. Martire B, Rondelli R, Soresina A, Pignata C, Broccoletti T, Finocchi A, Rossi P, Gattorno M, Rabusin M, Azzari C, Dellepiane RM, Pietrogrande MC, Trizzino A, Di Bartolomeo P, Martino S, Carpino L, Cossu F, Locatelli F, Maccario R, Pierani P, Putti MC, Stabile A, Notarangelo LD, Ugazio AG, Plebani A, De Mattia D: Clinical features, long-term follow-up and outcome of a large cohort of patients with Chronic Granulomatous Disease: an Italian multicenter study. Clin Immunol 2008, 126:155-164.

18. Deas DE, Mackey SA, McDonnell HT: Systemic disease and periodontitis: manifestations of neutrophil dysfunction. Periodontol 2000 2003, 32:82-104.

19. Beertsen W, Willenborg M, Everts V, Zirogianni A, Podschun R, Schroder B, Eskelinen EL, Saftig P: Impaired phagosomal maturation in neutrophils leads to periodontitis in lysosomal-associated membrane protein-2 knockout mice. J Immunol 2008, 180:475-482.

20. Daley TD, Armstrong JE: Oral manifestations of gastrointestinal diseases. Can J Gastroenterol 2007, 21:241-244.

21. Psoter WJ, Reid BC, Katz RV: Malnutrition and dental caries: a review of the literature. Caries Res 2005, 39:441-447.

22. Sanford AN, Suriano AR, Herche D, Dietzmann K, Sullivan KE: Abnormal apoptosis in chronic granulomatous disease and autoantibody production characteristic of lupus. Rheumatology (Oxford) 2006, 45:178-181.

23. Kinane DF, Mark Bartold P: Clinical relevance of the host responses of periodontitis. Periodontol 2000 2007, 43:278-293.

24. Bakri FG, Martel C, Khuri-Bulos N, Mahafzah A, El-Khateeb MS, AlWahadneh AM, Hayajneh WA, Hamamy HA, Maquet E, Molin M, Stasia MJ: First report of clinical, functional, and molecular investigation of chronic granulomatous disease in nine Jordanian families. J Clin Immunol 2009, 29:215-230.

25. Darwazeh AM, Pillai K: Prevalence of tongue lesions in 1013 Jordanian dental outpatients. Community Dent Oral Epidemiol 1993, 21:323-324.

26. Berg van den JM, van Koppen E, Ahlin A, Belohradsky BH, Bernatowska E, Corbeel L, Espanol T, Fischer A, Kurenko-Deptuch M, Mouy R, Petropoulou T, Roesler J, Seger R, Stasia MJ, Valerius NH, Weening RS, Wolach B, Roos D, Kuijpers TW: Chronic granulomatous disease: the European experience. PLOS ONE 2009, 4:e5234.

27. Levine S, Smith W, Malone M, Sebire NJ: Histopathological features of chronic granulomatous disease (CGD) in childhood. Histopathology 2005, 47:508-516.

28. Liese J, Kloos S, Jendrossek V, Petropoulou T, Wintergerst U, Notheis G, Gahr M, Belohradsky BH: Long-term follow-up and outcome of 39 patients with chronic granulomatous disease. J Pediatr 2000, 137:687-693.

29. Mouy R, Fischer A, Vilmer E, Seger R, Griscelli C: Incidence, severity, and prevention of infections in chronic granulomatous disease. J Pediatr 1989, 114:555-560.

30. Pihlstrom BL, Michalowicz BS, Johnson NW: Periodontal diseases. Lancet 2005, 366:1809-1820

31. Borrell LN, Taylor GW, Borgnakke WS, Nyquist LV, Woolfolk MW, Allen DJ, Lang WP: Factors influencing the effect of race on established periodontitis prevalence. J Public Health Dent 2003, 63:20-29.

32. Yoshie H, Kobayashi T, Tai H, Galicia JC: The role of genetic polymorphisms in periodontitis. Periodontol 2000 2007, 43:102-132.

33. Li Y, Xu L, Hasturk H, Kantarci A, DePalma SR, Van Dyke TE: Localized aggressive periodontitis is linked to human chromosome 1q25. Hum Genet 2004, 114:291-297.

34. Van Dyke TE, Levine MJ, Tabak LA, Genco RJ: Juvenile periodontitis as a model for neutrophil function: reduced binding of the complement chemotactic fragment, C5a. J Dent Res 1983, 62:870-872.

35. Schenkein HA: Finding genetic risk factors for periodontal diseases: is the climb worth the view?. Periodontol 2000 2002, 30:79-90.

36. Finn A, Hadzic N, Morgan G, Strobel S, Levinsky RJ: Prognosis of chronic granulomatous disease. Arch Dis Child 1990, 65:942-945.

doi:10.1186/1756-0500-3-37

Cite this article as: Dar-Odeh et al:: Orofacial findings in chronic granulomatous disease: report of twelve patients and review of the literature. BMC Research Notes 2010 3:37. 